\title{
Studies on Nanocrystalline TiN Coatings Prepared by Reactive Plasma Spraying
}

\author{
Dong Yanchun, Yan Dianran, He Jining, Zhang Jianxin, Xiao Lisong, and Li Xiangzhi \\ School of Material Science and Engineering, Hebei University of Technology, Tianjin 300130, China \\ Correspondence should be addressed to Dong Yanchun, dongrunyanchun@126.com
}

Received 21 May 2007; Revised 5 November 2007; Accepted 19 December 2007

Recommended by Junlan Wang

Titanium nitride (TiN) coatings with nanostructure were prepared on the surface of 45 steel (Fe- $0.45 \% \mathrm{C})$ via reactive plasma spraying (denoted as RPS) Ti powders using spraying gun with self-made reactive chamber. The microstructural characterization, phases constitute, grain size, microhardness, and wear resistance of TiN coatings were systematically investigated. The grain size was obtained through calculation using the Scherrer formula and observed by TEM. The results of X-ray diffraction and electron diffraction indicated that the TiN is main phase of the TiN coating. The forming mechanism of the nano-TiN was characterized by analyzing the SEM morphologies of surface of TiN coating and TiN drops sprayed on the surface of glass, and observing the temperature and velocity of plasma jet using Spray Watch. The tribological properties of the coating under nonlubricated condition were tested and compared with those of the AISI M2 high-speed steel and $\mathrm{Al}_{2} \mathrm{O}_{3}$ coating. The results have shown that the RPS TiN coating presents better wear resistance than the M2 high-speed steel and $\mathrm{Al}_{2} \mathrm{O}_{3}$ coating under nonlubricated condition. The microhardness of the cross-section and longitudinal section of the TiN coating was tested. The highest hardness of the cross-section of TiN coating is $1735.43 \mathrm{HV}_{100 \mathrm{~g}}$.

Copyright (c) 2008 Dong Yanchun et al. This is an open access article distributed under the Creative Commons Attribution License, which permits unrestricted use, distribution, and reproduction in any medium, provided the original work is properly cited.

\section{INTRODUCTION}

Titanium nitride (TiN) coatings are extensively applied in machinery industry due to their high hardness, low friction coefficient, beautiful color, excellent chemical stability, and wear resistance [1-6]. TiN has been produced by several techniques, which include direct nitridation of titanium metal, reductive nitridation of $\mathrm{TiCl}_{4}$, plasma synthesis, and laser synthesis. Direct nitridation of titanium metal powder by nitrogen has been well studied $[5,6]$. The formation of TiN is highly exothermic and the nitridation can be sustained to completion even at relatively low pressures of nitrogen. Chemical vapor deposition and plasma synthesis of titanium nitride involve the use of $\mathrm{TiCl}$ using ammonia as the nitriding agent. A vapor-phase chemical route using titanium tetrachloride, magnesium or sodium, and nitrogen in the temperature range $750-1050^{\circ} \mathrm{C}$ has been used in many studies [7-10]. Plasma processing in RF plasma torches has also been used to prepare titanium nitride [11-13]. The process involves the use of titanium halide or titanium metal powder with ammonia or nitrogen as the reactive gas. These coatings have deadly disadvantage, too. Namely, deposited efficiency is low (about $2 \sim 10 \mu \mathrm{m} / \mathrm{h}$ ), and producing complicated structural part is very difficult, and wear resistance in the high loading weight is not acceptable, therefore the application of TiN is restricted.

As known, bulk TiN has such an excellent corrosion resistance that most acidic and alkaline solutions cannot corrode it [14]. However, thin TiN coatings are not corrosion resistant to aqueous or gaseous media due to some pinholes existing in the coating $[10,11,14,15]$. Rickerby and Burnett found that the wear resistance of the coating improved as the thickness of the coating increased [16].

The disadvantage of these coatings can be overcome when TiN coating is prepared by plasma spraying. Because the deposited efficiency of plasma spraying is higher than that of other ways, and the thickness of coatings prepared by plasma spraying is bigger than that of other ways. The reactive plasma spraying (RPS) technology has been introduced in recent years as a promising way to develop dense composite coatings with a metallic or an intermetallic matrix and finely dispersed ceramic phases [17-19]. The wear 


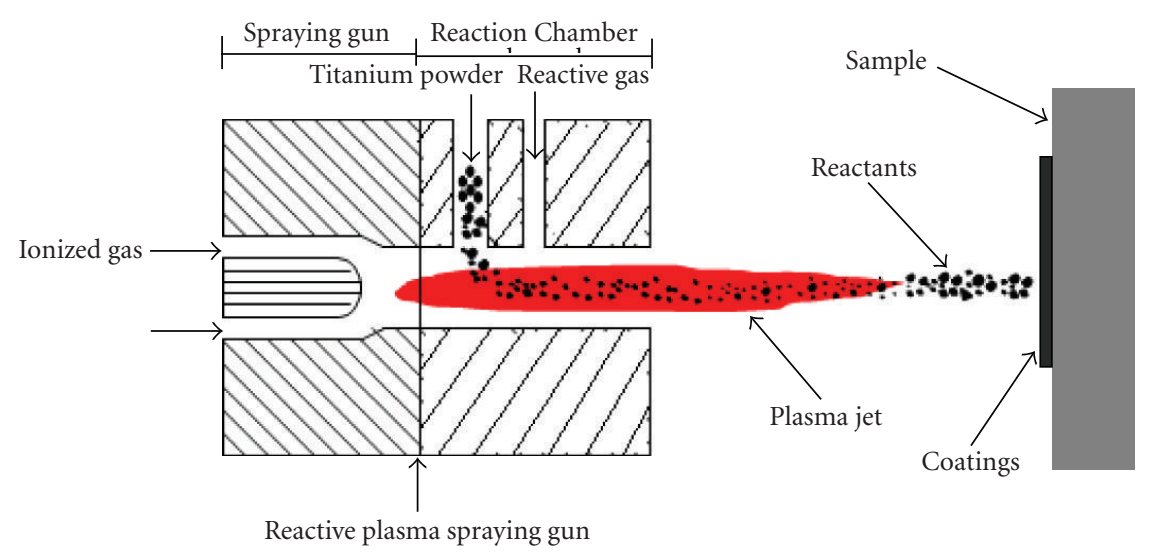

FIGURE 1: Sketch of the reactive plasma spraying gun.

resistance of plasma sprayed coatings can be enhanced by means of RPS techniques. Titanium nitride coatings developed via RPS are characterized by a considerable hardness, over $1500 \mathrm{HV}$, without the characteristic brittleness of TiN coatings obtained by physical vapor deposition (PVD), or chemical vapor deposition (CVD) $[20,21]$. In this paper, nanocrystalline TiN coating is prepared by spraying Ti powder with size of $30 \sim 40 \mu \mathrm{m}$ using plasma spray gun with selfmade reactive chamber which is filled with $\mathrm{N}_{2}$. The microstructure and property of nano-TiN coating are investigated in this paper.

\section{EXPERIMENTS}

\subsection{Materials}

The spraying equipment is LP-50B type, which is made in Jiujiang, China, and its standard power is $50 \mathrm{Kw}$. The spraying gun is assembled using a BT-G3 type plasma spraying gun and a reactive chamber which is self-designed and prepared [22]. The sketch of reactive plasma spraying gun is shown in Figure 1. The pure titanium powder used in the present work is commercially available and produced by Beijing General Research Institute of Mining and Metallurgy, China. The average particle size distribution of the titanium powder is about $30 \sim 40 \mu \mathrm{m}$. The substrate material is 45 (Fe$0.45 \mathrm{wt} . \% \mathrm{C}$ ) steel, which is machined into samples of $30 \mathrm{~mm}$ $\times 25 \mathrm{~mm} \times 10 \mathrm{~mm}$ and ground to rough surfaces. Prior to spraying TiN coating, Ni-10 wt.\%Al self-melting alloy bond layer with a thickness of about $100 \mu \mathrm{m}$ is sprayed onto surfaces of samples, for increasing the adhesive strength between the TiN coating and substrate.

\subsection{Fabrication and characterization of the TiN coating}

During spraying, the titanium powders, the micrograph of which was shown in Figure 2, were carried by nitrogen gas into the reactive chamber of the RPS gun, where pure nitrogen gas was also introduced. $\mathrm{Ti}$ and $\mathrm{N}_{2}$ reacted in the reactive chamber, the product, which was TiN, deposited

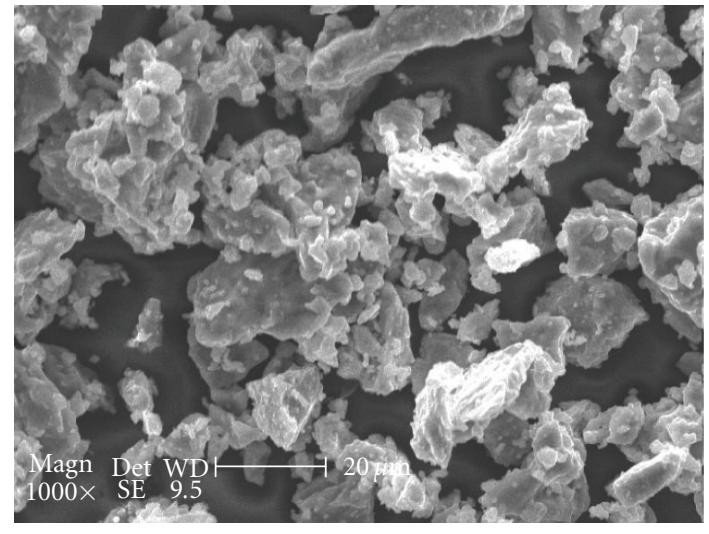

FIgURE 2: SEM micrograph of the original Ti powders.

on the substrate. Thus, a coating with a thickness of at least $400 \mu \mathrm{m}$ was fabricated within a few minutes. The morphology of the as-sprayed TiN coating was observed by means of a PHILIPS XL30/TMP scanning electron microscope (SEM) and PHILIPS TECNAI F20 transmission electron microscope (TEM). The JEOL Rigaku X-ray diffractometer 2500/PC diffraction instrument with $\mathrm{Cu}$ target was adopted to analyze the phase composition of the coating's exposed surface and cross-section. The grain size of the TiN coating was calculated according to Scherrer formula [23]:

$$
D_{h k l}=\frac{k \lambda}{B \cos \theta}, \quad B=\sqrt{B_{1}^{2}-B_{2}^{2}},
$$

where " $D_{h k l}$ " is the average diameter in $n m$, " $k$ " is the shape factor (0.9), " $B$ " is the broadening of the diffraction line measured half of its maximum intensity in "radians," " $B_{1}$ " is the half peak breadth of the diffraction line of test sample, " $B_{2}$ " is half peak breadth of the diffraction line of micron crystal TiN specimen prepared by other way, " $\lambda$ " is the wave length of $\mathrm{X}$-ray, and " $\theta$ " is the Bragg diffraction angle.

Spray Watch used during spraying is observation system for thermal spraying, made by Oseir Co., Ltd., Finland. 


\subsection{Hardness test}

Microhardness of the cross and longitudinal sectional TiN coating was measured using the digital Vickers microhardness tester, which is made in Shanghai Taiming Optical Instrument Co., Ltd., China. Loads ranging from 25 to $1000 \mathrm{~g}$ and a dwell time of 15 seconds were selected. Approximately, 10 indentations were made for each load. The distance between every two indentations was controlled three times longer than the indentation diagonal, so the stress field effect near the indentation can be eliminated. The average microhardness is selected for discussion in this paper.

\subsection{Wear tests}

Friction and wear tests of the TiN coated specimens were performed using a block-on-ring sliding apparatus, under nonlubricated condition. The MM-200 wear test machine, made by Xuanhua Material Test Machine Co., Ltd., China, was operated with the sliding speed of $0.4 \mathrm{~ms}^{-1}$. The test specimens were fixed by a sample holder; the wear rings were placed under the specimens; loads ranging from 100 to $1470 \mathrm{~N}$ were vertically applied at the top of specimens. For each load, three specimens were tested, and the average wear volume loss was taken. The wear ring used was AISI E52100 steel (0.95-1.05C, 0.2-0.4 Mn, 0.15-0.35 Si, 1.3-1.65 Cr, 0.3 Ni, 0.25 Cu, and bal $\mathrm{Fe}$ ) (in wt.\%). The ring is $38 \mathrm{~mm}$ in external diameter and $10 \mathrm{~mm}$ in thickness, which was heat-treated to an average hardness of about $60 \mathrm{HRC}$. Each wear test was conducted for 60 minutes. Wear loss of TiN coating, $\mathrm{Al}_{2} \mathrm{O}_{3}$ coating, and the AISI M2 steel specimens were obtained by measuring the volumetric loss after each test according to (2). The friction coefficient (FC) of the specimens was given by (3):

$$
\begin{aligned}
\Delta V & =B \times\left[r^{2} \times \operatorname{Sin}^{-1}\left(\frac{b}{2 r}\right)-\frac{b}{2}\left(r^{2}-\frac{b^{2}}{4}\right)^{1 / 2}\right], \\
\mu & =\frac{T}{r \cdot P} \times \frac{\alpha+\sin \alpha \cdot \cos \alpha}{2 \sin \alpha},
\end{aligned}
$$

where $\Delta V$ is the volumetric loss of specimens; $B$ and $r$ are, respectively, the thickness and radius of the ring; $b$ is the width of worn scars; $T$ is the wear moment; $P$ is the load employed; $\alpha$ is the contacted angle, according to $\alpha=\sin ^{-1}(b / 2 r)$, and $\mu$ is friction coefficient.

\section{RESULTS}

\subsection{Phases constitute of the TiN coating}

Figure 3 is XRD pattern of the TiN coating sprayed on the surface of substrate and pure Ti powders. The coating is mainly composed of two phases, TiN and small quantities of $\mathrm{Ti}_{3} \mathrm{O}$, without pure Ti. Observing the spectrum, five sharp TiN diffraction peaks appeared, and the diffraction planes are (111), (200), (220), (311), and (222). Intensities of $\mathrm{Ti}_{3} \mathrm{O}$ are very low, the diffraction planes of the $\mathrm{Ti}_{3} \mathrm{O}$ phase are (103), (113), (116), and (223). According to the Scherrer formula, the grain size of TiN coating was estimated, which was shown in Table 1 . The grain size of the TiN coating

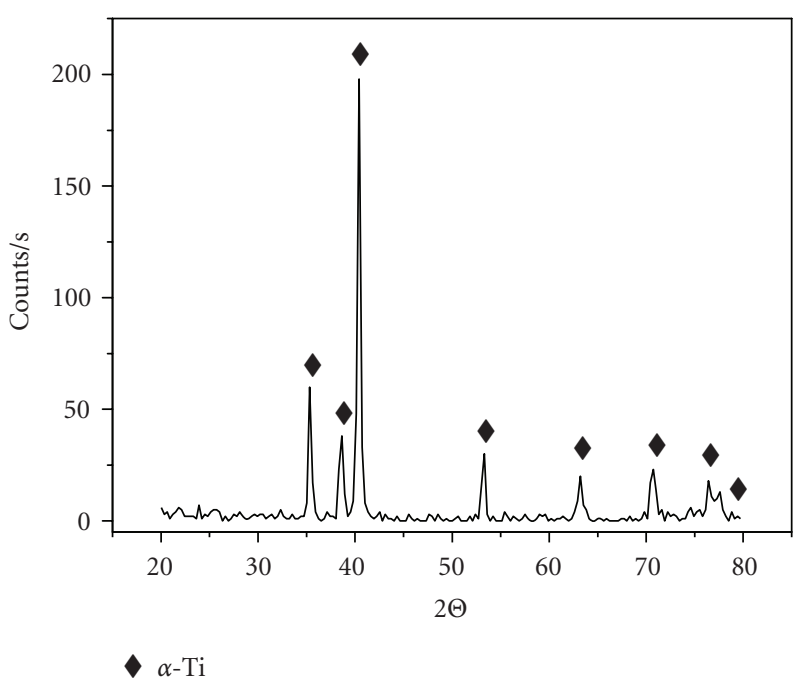

(a)

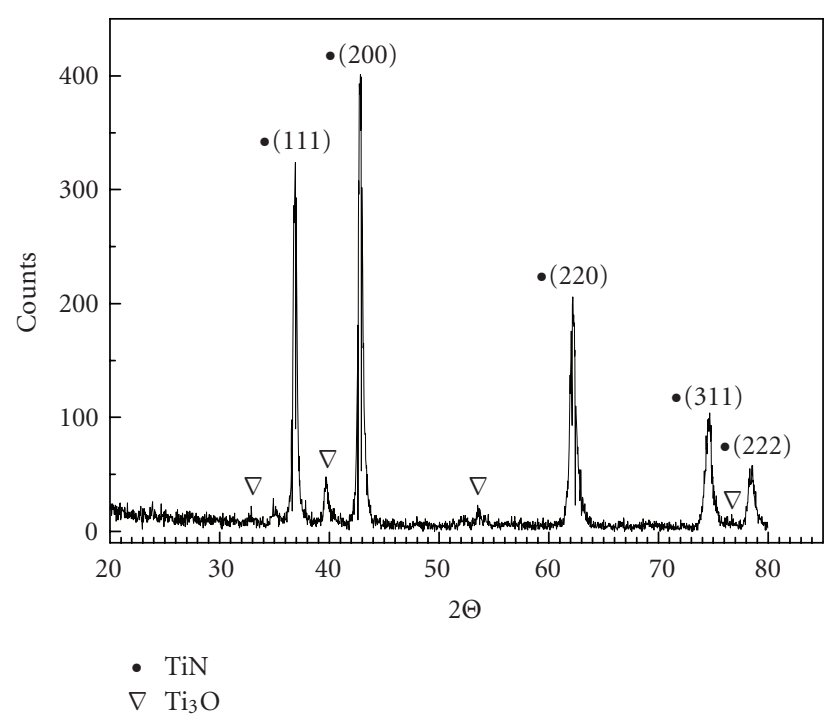

(b)

FIGURE 3: Surface XRD pattern of original Ti powders and the reactive plasma sprayed TiN coating.

ranged $78 \sim 97 \mathrm{~nm}$, which is consistent with what is observed by TEM (see Figure 5). Pure Ti diffraction does not appear in the coating, which proves that the $\mathrm{Ti}$ and $\mathrm{N}_{2}$ react fully in RPS process. This is consistent with literature [9]. $\mathrm{Ti}_{3} \mathrm{O}$ is metastable solid solution, which comes from Ti unsufficient oxidation at temperature of $650 \sim 750^{\circ} \mathrm{C}$ and decomposes when temperature exceeds $750^{\circ} \mathrm{C}$ [24]. The $\mathrm{Ti}_{3} \mathrm{O}$ in the coating is product of the oxidation of TiN and exists in the coating for shock cooling under plasma spraying condition.

\subsection{Microstructural characterization of the TiN coating}

The SEM photograph of the TiN coating cross-section is shown in Figure 4 . The entire cross-sectional morphology of 


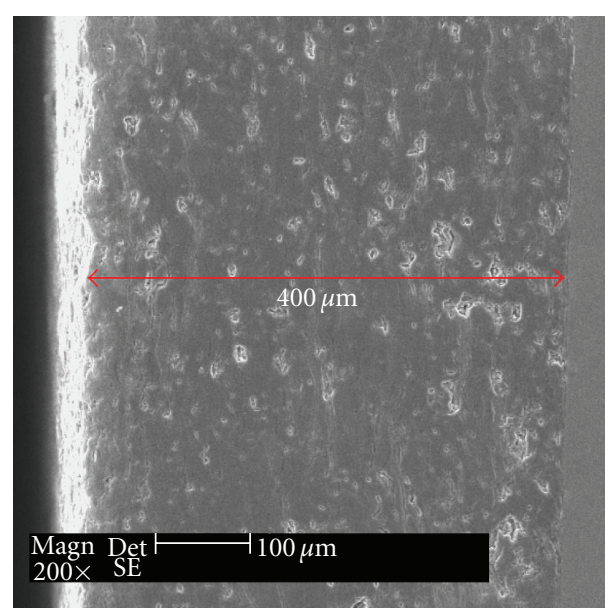

(a)

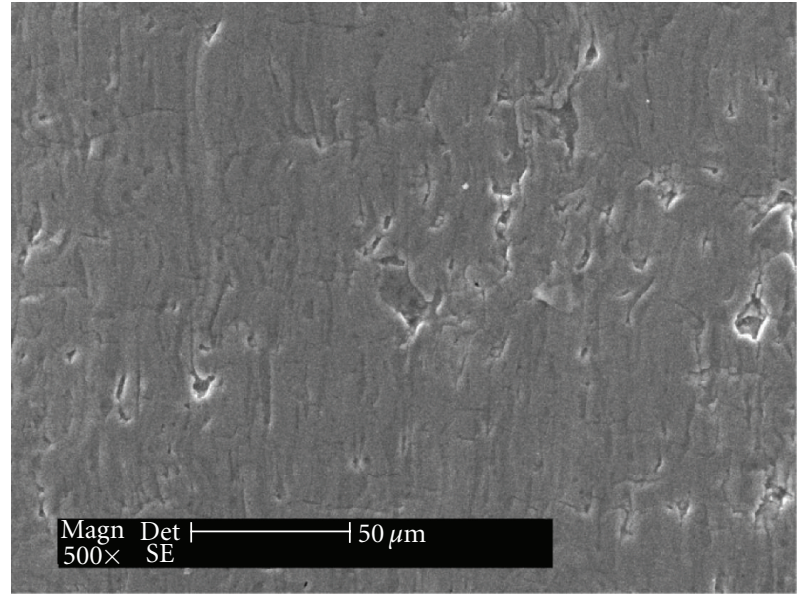

(b)

FIGURE 4: The cross-sectional morphologies of the RPS TiN coating, (b) is partial enlarged drawing of (a).

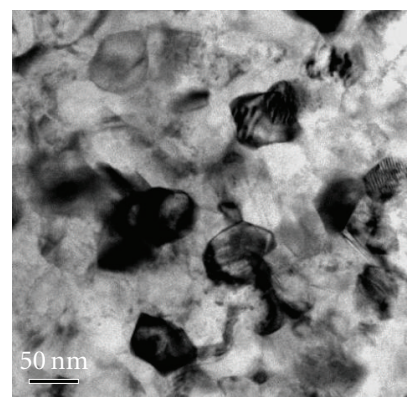

(a)

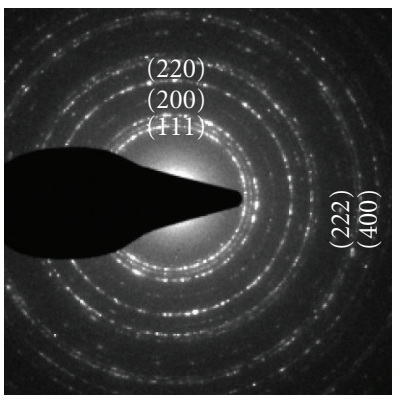

(b)

FIGURE 5: TEM morphology of the reactive plasma sprayed TiN coating: (a) nanocrystallines, (b) the selected area electron diffraction pattern.

the RPS TiN coating in Figure 4(a) indicates that its thickness is $420 \mu \mathrm{m}$, which is about 100 times than that of TiN films prepared by CVD or PVD. The coating presents layer structure, which is tightly piled. The structure with few pores should be attributed to gas which exists between the TiN liquid drops and has no time to be released during coating forming. Small quantities of cracks appear in the multilayered structures of the coating (see Figure 4(b)). Further study is needed to reduce the pores and cracks, and improve the structure of the coating.

TEM is an indispensable analytical tool in the study of the microstructure of coatings. Figure 5 indicates the TEM morphology and the selected area electron diffraction (SAED) pattern of the reactive plasma sprayed TiN coating. It can be seen from Figure 5(a) that the most of grain size of the coating is smaller than $100 \mathrm{~nm}$. The SAED pattern of the coating is given in Figure 5(b). The grain size of $82 \pm 10 \mathrm{~nm}$ was measured by linear intercepting, which is approximate to the result obtained by calculation, and smaller than that of the original Ti powders, which is $30 \sim 40 \mu \mathrm{m}$. The diffraction rings of the SAED pattern in Figure 5(b) are continuous,
TABLE 1: Scherrer crystallite sizes of the TiN coatings.

\begin{tabular}{lccc}
\hline Diffraction plane $(h k l)$ & $(111)$ & $(200)$ & $(220)$ \\
\hline $\mathrm{D}_{h k l}(\mathrm{~nm})$ & $92 \sim 97$ & $83 \sim 88$ & $78 \sim 83$ \\
\hline
\end{tabular}

dense, and broader, which indicates the (111), (200), and (220) orientation. (311) orientation is not clear. The diffraction rings show that the orientation of TiN crystal grains is random. Weak diffraction spots distribute in diffraction rings because the size of small quantity of crystal grains is bigger than $100 \mathrm{~nm}$. XRD and SAED examinations revealed that the TiN coating has the cubic structure of $\mathrm{NaCl}$ type ( $a$ $=0.42 \mathrm{~nm}$ ).

\subsection{Microhardness of the TiN coating}

It is well known that the apparent microhardness of solid materials depends on the applied indentation test load. This phenomenon is known as the indentation size effect (ISE). Figure 6 shows the dependence of the microhardness for the 


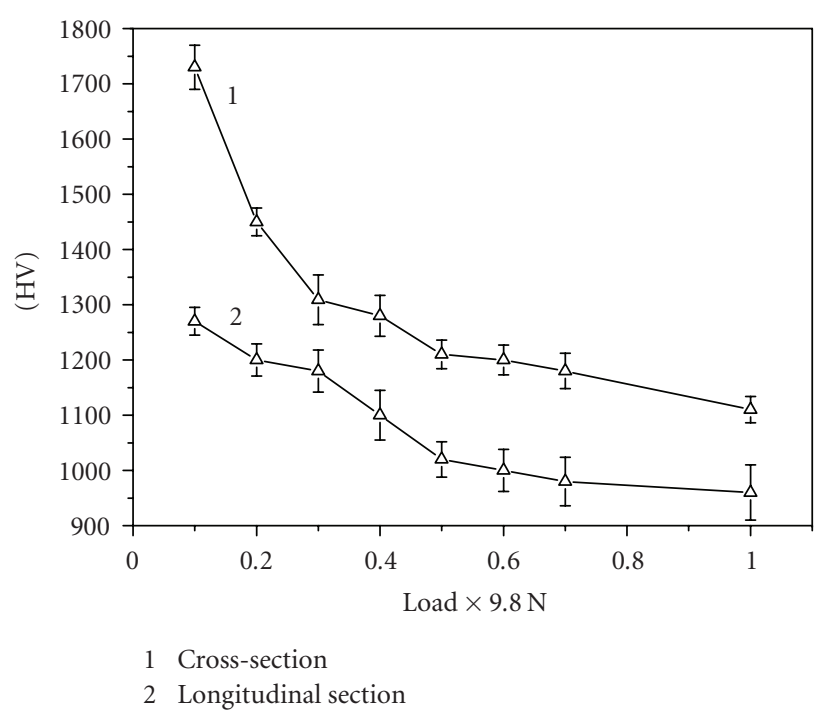

FIgURE 6: The microhardness of TiN coating longitudinal section and cross-section.

cross-sectional and longitudinal-sectional RPS TiN coating on the indentation loads. As the applied load ranges from 100 to $1000 \mathrm{~g}$, the Vickers microhardness drops from 1735.43 to 1125.27 HV and 1267.78 to $962.26 \mathrm{HV}$, respectively, which is an evident phenomenon of ISE. When the test load is standard load of $100 \mathrm{~g}$, the microhardness is $1189.36 \mathrm{HV}$.

\subsection{Volumetric wear loss of TiN coating specimens}

In order to study the wear resistance of the TiN coating, the test load changes from $100 \sim 1470 \mathrm{~N}$. For $\mathrm{Al}_{2} \mathrm{O}_{3}$ ceramic coating cannot resist wear of high load, when the test load is higher than $500 \mathrm{~N}$, the friction coefficient increases notably, and friction noise is high. M2 high-speed steel is selected as the comparison samples when test load is above $500 \mathrm{~N}$. Figure 7 (a) shows the volumetric wear loss of the $\mathrm{Al}_{2} \mathrm{O}_{3}$ coating and TiN coating at loads between 100 and $500 \mathrm{~N}$ and at $0.4 \mathrm{~ms}^{-1}$; Figure 7(b) shows the volumetric wear loss of TiN coating and M2 high-speed steel at loads between 500 and $1470 \mathrm{~N}$. The volumetric wear loss of the $\mathrm{Al}_{2} \mathrm{O}_{3}$ coating, the TiN coating, and M2 steel increases with the loads increased. Under low loads $(100 \sim 500 \mathrm{~N})$, the volumetric wear loss of the $\mathrm{Al}_{2} \mathrm{O}_{3}$ coating is bigger than that of the TiN coating. When the load changes from $490 \sim 980 \mathrm{~N}$, the TiN coating and M2 high-speed steel are close in wear loss. With the continuous increase of the loads, the TiN coating remained a mild increase in wear loss, and reached $6.86 \mathrm{~mm}^{3}$ when the load is up to $1470 \mathrm{~N}$, while the curve of the M2 steel's volumetric wear loss versus loads presents distinctly moving up tend. The volumetric wear loss of the TiN coating is approximately half under $1225 \mathrm{~N}$ and two-fifths of that of the M2 high-speed steel under $1470 \mathrm{~N}$, respectively. Figure 7 indicated that the wear resistance of the TiN coating is better than $\mathrm{Al}_{2} \mathrm{O}_{3}$ coating and $\mathrm{M} 2$ high-speed steel.

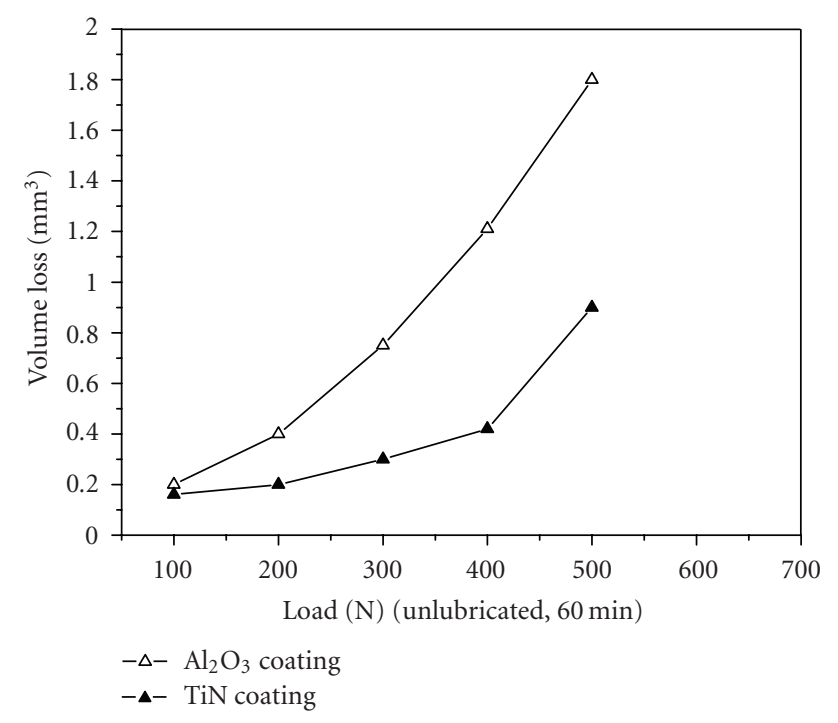

(a)

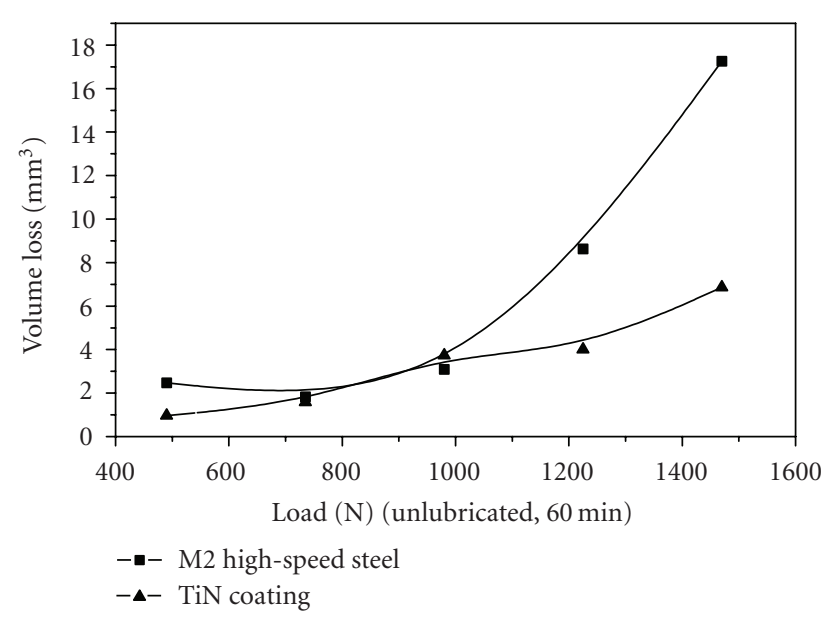

(b)

FIgure 7: Wear volume loss of the TiN coating, $\mathrm{Al}_{2} \mathrm{O}_{3}$ coating, and M2 steel plotted as a function of loads: (a) load is smaller than $500 \mathrm{~N}$, (b) load is bigger than $500 \mathrm{~N}$.

\subsection{Friction coefficient of TiN coating and M2 high-speed steel}

Figure 8 presents the dependence of friction coefficient on loads of both the TiN coating and the M2 steel under dry sliding wear. It can be seen from the curves that with the increase of loads, the FC of the TiN coating and AISI M2 steel generally changes in a small range of about $0.372 \sim 0.412$ and $0.331 \sim 0.375$, respectively. The two are close in friction coefficient when load is $1470 \mathrm{~N}$. Therefore, the antifriction property of TiN coating is close to that of the AISI M2 steel at dry sliding wear under heavy loads.

\subsection{Analyses and discussion}

Figure 9 shows the surface layer morphologies of a few TiN drops sprayed on the surface of glass and the TiN coating 


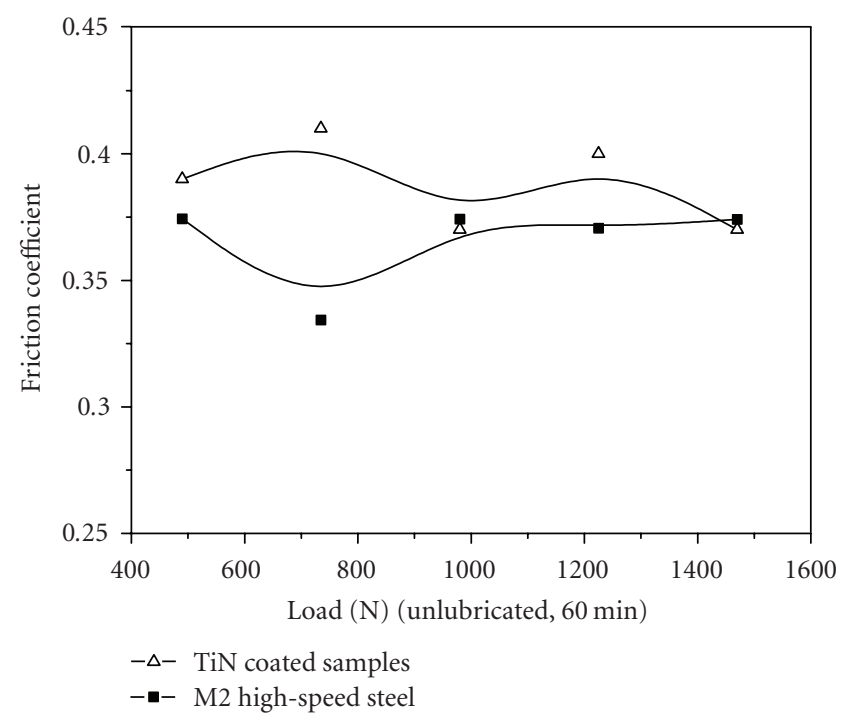

FIgURE 8: Friction coefficients of the TiN coating and M2 steel plotted as a function of loads.

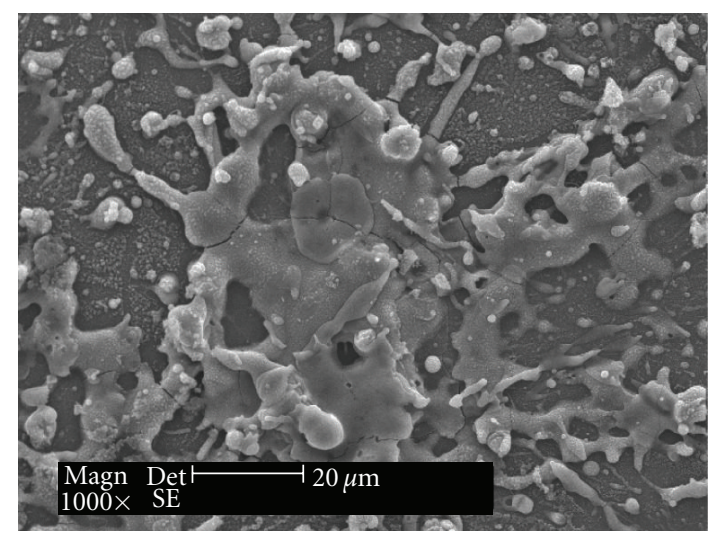

(a)

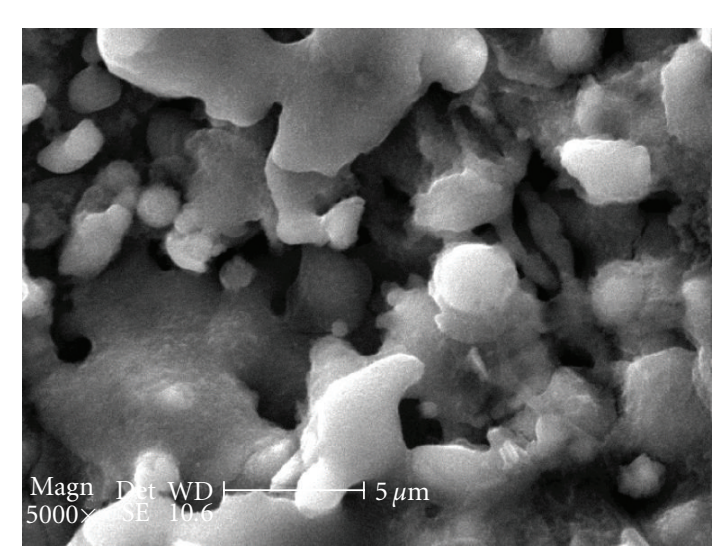

(b)

FIGURE 9: Surface morphologies of the TiN sprayed on the glass and the TiN coating: (a) the TiN on the glass, (b) the TiN coating.

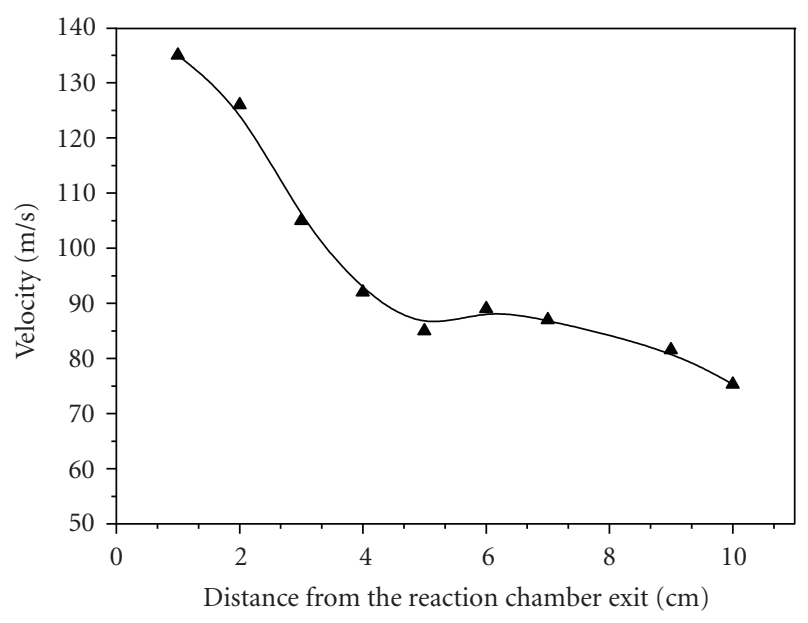

(a)

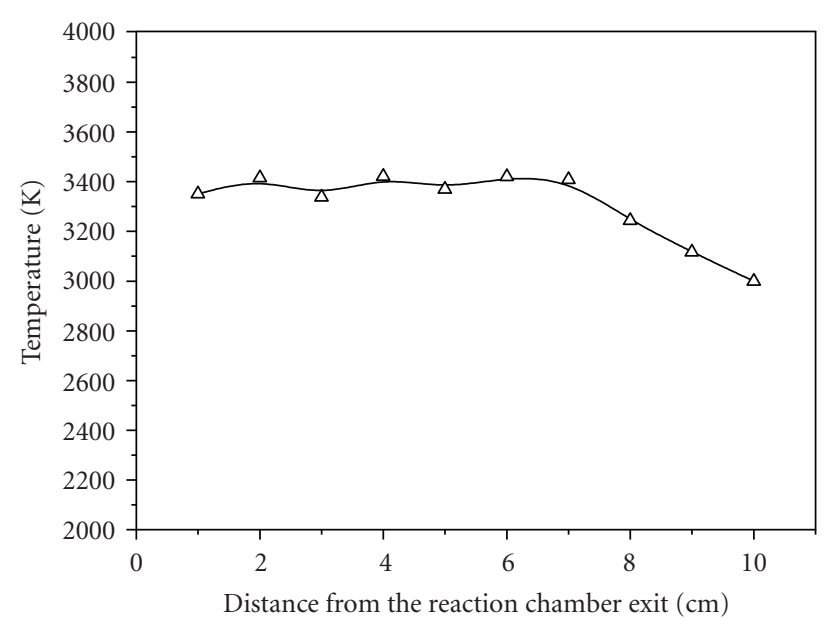

(b)

FIGURE 10: The velocity and temperature of the particles in plasma jet when the RPS state is steady, which are measured by Spray Watch: (a) the velocity of the particle, (b) the temperature of the particle.

under same spraying condition. Obviously, the topography of TiN drops on the glass surface presents the character of high-temperature molten drop spattering. It is indicated that the coating is deposited with molten drops. The forming process of the TiN coating is that the molten reactants remain in liquid state in the plasma jet, spatter, spread, deform, and freeze on the sample surface. Owing to the fact that the temperature gradient from plasma jet to the sample surface is so big that the molten drops nucleate quickly, but nucleates have no time to grow, therefore the grain of the TiN is refined.

Solid Ti particles are melted in high temperature plasma jet and acutely reacted with $\mathrm{N}_{2}$ ion gas and $\mathrm{N}_{2}$ gas in reactive chamber, while a great deal of reaction heat is given out. The reaction belongs to combustion synthesis [25]. As a result, the temperature of the liquid particle increases. When the spraying state is steady, the velocity and temperature of the particles in plasma jet are measured by Spray Watch. Figure 10 shows the temperature and the velocity of the 
particles flying in plasma jet. It can be seen that the velocity of particle decreases with its flying distance to reactive chamber exit increasing, while the temperature of the particles remains steady, which is different to normal plasma spray. For normal plasma spray, the temperature of particle decreases with the distance increasing. The reaction heat reinforces the heat of the plasma jet and has particles remained liquid before it reaches to metal substrate. The measured average velocity and temperature of particles arriving to substrate are $105 \mathrm{~m} / \mathrm{s}$ and $3360 \mathrm{~K}$, respectively (see Figure 10). The molten point of TiN is $3223 \mathrm{~K}$, which is lower than $3360 \mathrm{~K}$. During spraying, the distance $(/)$ from metal substrate to spray gun exit is $100 \mathrm{~mm}$. The time $(t)$ in which a particle arrives to substrate from reactive chamber is

$$
t=\frac{l}{v}=\frac{100 \times 10^{-3} \mathrm{~m}}{105 \mathrm{~m} / \mathrm{s}}=0.95 \times 10^{-3} \mathrm{~s} .
$$

In so short time, the TiN drops quench from $3360 \mathrm{~K}$ to about $800 \mathrm{~K}$ and quickly freeze; the cooling rate is higher than general plasma spraying. The Huge cooling velocity and undercooling increase the nucleation rate. The reason for forming nanocrystal TiN coating is that combustion synthesis between $\mathrm{Ti}$ and $\mathrm{N}_{2}$ and plasma spraying condition coacts. Combustion synthesis reaction in plasma jet fabricates liquid TiN with high temperature. TiN liquid drops, shockcooling under the plasma spraying condition, solidify and form nanocrystal TiN coatings on substrates.

\section{CONCLUSIONS}

(1) The TiN coating, prepared via RPS Ti powders using spraying gun with self-made reactive chamber, is mainly composed of two phases, TiN and small quantities of $\mathrm{Ti}_{3} \mathrm{O}$. TiN coatings present typical layer structure. The size of most of crystal grains in the TiN coating is smaller than $100 \mathrm{~nm}$.

(2) The forming mechanism of the nanostructure coating is that Ti powders are melted and reacted with $\mathrm{N}_{2}$ in plasma jet and in the chamber. Heat given out by combustion synthesis reaction increases the temperature of molten drops. The Huge cooling velocity and degree of supercooling under plasma spraying condition have the drops quench, nucleate quickly, and form nanostructure.

(3) The highest hardness of the TiN coating is 1735 $.43 \mathrm{HV}_{100 \mathrm{~g}}$; the wear resistance of the coating is better than that of $\mathrm{Al}_{2} \mathrm{O}_{3}$ coating and $\mathrm{M} 2$ high-speed steel.

\section{ACKNOWLEDGMENT}

This work was supported by the National Natural Science Foundation of China (no. 50472033).

\section{REFERENCES}

[1] H. Dingjun, H. Shejun, and X. Guangrong, "Application and research development of TiN coating," Transaction of Guangdong University of Technology, vol. 22, no. 2, 2005.
[2] H. A. Jehn, "Multicomponent and multiphase hard coatings for tribological applications," Surface and Coatings Technology, vol. 131, no. 1-3, pp. 433-440, 2000.

[3] J. G. Han, J. S. Yoon, H. J. Kim, and K. Song, "High temperature wear resistance of (TiAl)N films synthesized by cathodic arc plasma deposition," Surface and Coatings Technology, vol. 86-87, part 1, pp. 82-87, 1996.

[4] L. Jiwen and Y. Li, "Characteristics of low temperature ion plating TiN coatings," Chinese Journal of Mechanical Engineering, vol. 11, no. 2, pp. 136-140, 1998.

[5] L. Wenmei and H. Jiawen, "Oxidation resistant properties of vapor deposited TiN, Ti (C, N) coatings," Materials for Mechanical Engineering, vol. 21, no. 4, 1997.

[6] C. Jimenez, S. Gilles, R. Doppelt, et al., "CVD of TiN and other barrier metals," Surface and Coatings Technology, vol. 31, pp. 33-46, 1995.

[7] S. Wilson and A. T. Alpas, "Wear mechanism maps for TiNcoated high speed steel," Surface and Coatings Technology, vol. 120-121, pp. 519-527, 1999.

[8] T. S. Li, H. Li, and F. Pan, "Microstructure and nanoindentation hardness of Ti/TiN multilayered films," Surface and Coatings Technology, vol. 137, no. 2-3, pp. 225-229, 2001.

[9] A. Kobayashi, "Formation of TiN coatings by gas tunnel type plasma reactive spraying," Surface and Coatings Technology, vol. 132, no. 2-3, pp. 152-157, 2000.

[10] R. Motte, M. Proust, J. Torres, et al., "TiN-CVD process optimization for integration with Cu-CVD," Microelectronic Engineering, vol. 50, no. 1-4, pp. 369-374, 2000.

[11] M. Kawamura, K. Kumagai, Y. Abe, K. Sasaki, and H. Yanagisawa, "Characterization of TiN films prepared by rf sputtering using metal and compound targets," Vacuum, vol. 51, no. 3, pp. 377-380, 1998.

[12] R. M. Marin-Ayral, C. Pascal, F. Martinez, and J. C. Tedenac, "Simultaneous synthesis and densification of titanium nitride by high pressure combustion synthesis," Journal of the European Ceramic Society, vol. 20, no. 14-15, pp. 2679-2684, 2000.

[13] P. V. Ananthapadmanabhan, P. R. Taylor, and W. Zhu, "Synthesis of titanium nitride in a thermal plasma reactor," Journal of Alloys and Compounds, vol. 287, no. 1-2, pp. 126-129, 1999.

[14] H. Kuwahara, N. Mazaki, M. Takahashi, T. Watanabe, X. Yang, and T. Aizawa, "Mechanical properties of bulk sintered titanium nitride ceramics," Materials Science and Engineering A, vol. 319-321, pp. 687-691, 2001.

[15] T. Valente and F. P. Galliano, "Corrosion resistance properties of reactive plasma-sprayed titanium composite coatings," Surface and Coatings Technology, vol. 127, no. 1, pp. 86-92, 2000.

[16] D. S. Rickerby and P. J. Burnett, "The wear and erosion resistance of hard pvd coatings," Surface and Coatings Technology, vol. 33, pp. 191-211, 1987.

[17] P. V. Ananthapadmanabhan and P. R. Taylor, "Titanium carbide-iron composite coatings by reactive plasma spraying of limonite," Journal of Alloys and Compounds, vol. 287, no. 12, pp. 121-125, 1999.

[18] A. Kobayashi, "New applied technology of plasma heat source," Welding International, vol. 4, no. 4, pp. 276-282, 1990.

[19] T. Valente and F. P. Galliano, "Corrosion resistance properties of reactive plasma-sprayed titanium composite coatings," Surface and Coatings Technology, vol. 127, no. 1, pp. 86-92, 2000.

[20] E. Galvanetto, F. P. Galliano, F. Borgioli, U. Bardi, and A. Lavacchi, "XRD and XPS study on reactive plasma sprayed titanium-titanium nitride coatings," Thin Solid Films, vol. 384, no. 2, pp. 223-229, 2001. 
[21] W. Feng, D. Yan, J. He, et al., "Microhardness and toughness of the TiN coating prepared by reactive plasma spraying," Applied Surface Science, vol. 243, no. 1-4, pp. 204-213, 2005.

[22] Y. Dianran, H. Jining, and D. Yanchun, "Plasma spraying reactive chamber equipment $(\mathrm{P})$ Cina," Patent no. ZLCN200410072552.X, 2007.

[23] A. Akbari, J. P. Riviere, C. Templier, et al., "Structural and mechanical properties of IBAD deposited nanocomposite TiNi-N coatings," Surface and Coatings Technology, vol. 200, pp. 6298-6302, 2006.

[24] S. Malinov, W. Sha, and C. S. Voon, "In situ high temperature microscopy study of the surface oxidation and phase transformations in titanium alloys," Journal of Microscopy, vol. 207, no. 3, pp. 163-168, 2002.

[25] Y. Sheng, Combustion Synthesis, vol. 7, Metallurgical Industry, Beijing, China, 1999. 

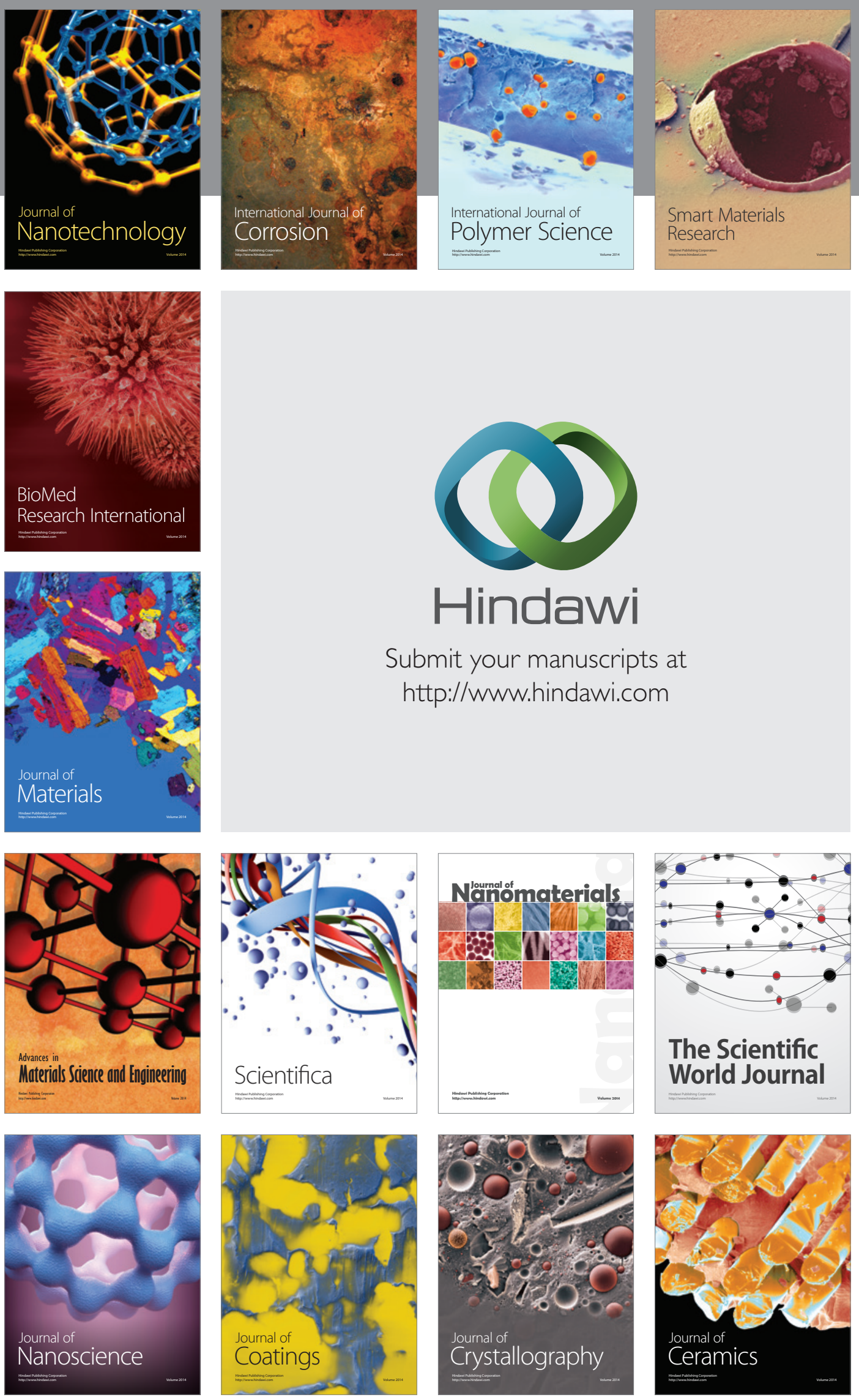

The Scientific World Journal

Submit your manuscripts at

http://www.hindawi.com

\section{World Journal}

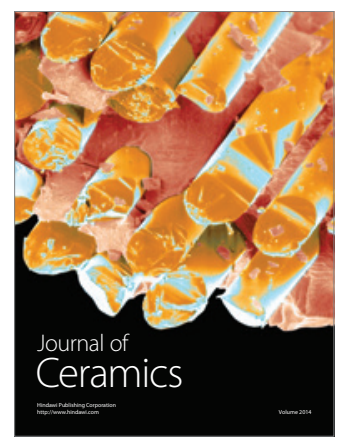

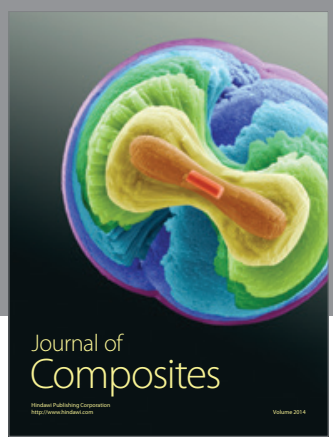
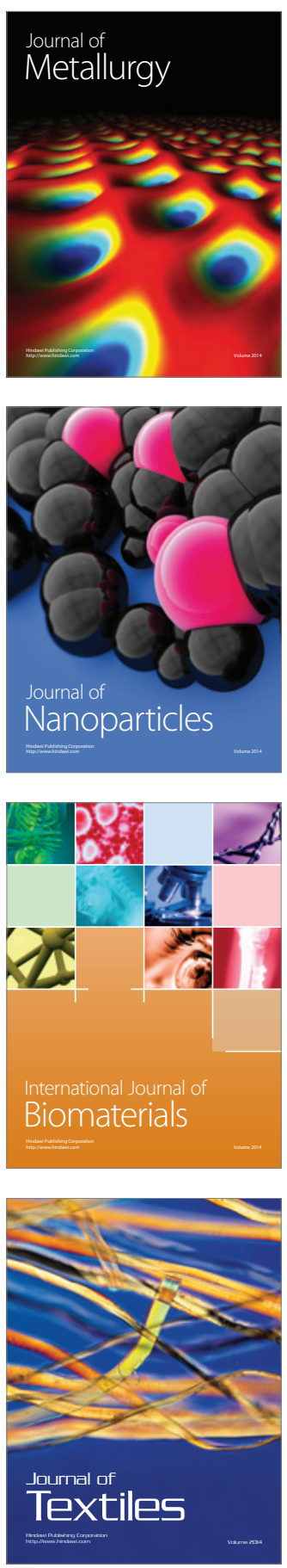